\title{
O cinema documentário na era da imagem técnica pós-fotográfica ${ }^{1}$
}

\section{The documentary in the post-photographic image era}

Marcelo Prioste ${ }^{2}$ de 2015. da ECA, a Revista Movimento (www.revistamovimento.net). Professor na PUC-SP (Multimeios, Jornalismo, Diálogos entre Filosofia, Cinema e Humanidades e Estéticas das Mídias). No doutorado desenvolveu pesquisa sobre o cinema documentário latino-americano com enfoque na produção do cineasta cubano Santiago Álvarez Román (1919-1998). E-mail: priost@uol.com.br. 


\section{Resumo}

O presente artigo propõe uma conjetura sobre o impacto da atual imagem técnica digital procedente dos softwares de simulação e videogames na realização do cinema documentário contemporâneo. Descrita como artificial, desindexada do real e, portanto, pós-fotográfica, esta imagética promove um contraponto à tradição primordial do documentarismo baseado na imagem de origem fotográfica, o fotograma. Nesta abordagem há uma convergência na direção dos documentários de enredos históricos, pelo potencial de reinvenção e reinterpretação de relatos e episódios da História neles contidos.

Palavras-chave

Documentário, imagem, videogames, digital, pós-fotografia.

\section{Abstract}

This article proposes a conjecture about the impact of the current digital technical image from simulation software and videogames in the realization of contemporary documentary cinema. Described as artificial, unreal and therefore post-photographic, this imagery promotes another look to the primordial tradition of documentarism based on the photographic image. In this approach there is a convergence in the direction of historical purpose documentaries, by the potential in them contained of reinvention and reinterpretation of stories and episodes of History.

\section{Keywords}

Documentary, image, videogames, digital, post-photography. 
Ao pensarmos no âmbito do quadro midiático contemporâneo marcado por um intenso e quase onipresente sistema digital - uma quinta geração de máquinas reprodutoras de imagens (DUBOIS, 2004) que se enredam desde antes do século $\mathrm{XX}-$, consideramos desde os artefatos óticos de pré-inscrição da pintura, passando pela técnica fotográfica, pelo dispositivo cinematográfico e pela produção e difusão do sistema televisivo. Um cenário em que se conjetura sobre qual seria o impacto da atual imagem técnica digital, artificial e desindexada do real nas formas de produção do cinema documentário contemporâneo, principalmente em relação ao documentário histórico, que estabelece um contraponto à tradição imanente do documentarismo, o basear-se na imagem fotográfica, o fotograma.

Partindo de sua gênese, o cinema documentário decorre da convergência de quatro eixos conceituais logo nas primeiras décadas do século XX (NICHOLS, 1991). O primeiro eixo tem o cinema como registro do real, em que a imagem projetada na tela evidenciava algo do mundo material, na perspectiva de um cinema visto com o potencial de um instrumento científico que, por sua vez, faria da câmera um instrumento capaz de ultrapassar os limites do olho humano ao perscrutar um determinado fenômeno físico.

O segundo eixo de formação seria proveniente, em grande parte, das experimentações artísticas promovidas pelas vanguardas modernas da Europa no período entreguerras. A fotogenia, fenômeno capaz de reinventar a imagem no interior da matéria fílmica, aliada às técnicas de montagem, deram o instrumental para que a "voz" do cineasta ganhasse corpo. Neste momento, o cinema documentário aprimorou em muito seu potencial como interpretador de realidades. Observa-se então a formação de um terceiro eixo que, compartilhado com o cinema ficcional, oferece os recursos de narratividade e a edificação de personagens, estabelecendo estruturas com início, meio e fim a partir de uma dinâmica entre problemas e soluções (o desfecho) por onde transitam protagonistas e antagonistas.

Por fim, com a convergência dos três eixos anteriores, emerge a oratória retórica, ou seja, o discurso do documentarista se articula por meio da trama e 
estabelece um consistente e persuasivo ponto de vista sobre o mundo histórico. Ou, como diz a célebre síntese de Bill Nichols (2001, p. 134): "O exibidor de atrações, o contador de histórias e o poeta da fotogenia condensam-se na figura do documentarista como um orador que fala com uma voz toda sua do mundo que todos compartilhamos".

Fundamentado por esta premissa, os apontamentos a serem descritos aqui voltam-se majoritariamente ao primeiro eixo, trazendo uma breve reflexão sobre como o cinema, aparato técnico, tem a capacidade de recriar fatos do mundo a partir de relatos e testemunhos. Ao imaginarmos a imagem técnica de origem digital como forma de expressão contemporânea capaz de se articular tanto no âmbito coletivo (mídia e redes), quanto no indivíduo (arquivos pessoais e dispositivos móveis), é previsível que o documentário dela se aproprie como matéria-prima imprescindível à representação do quadro hodierno, expandindo o argumento de Nichols ao apontar que: "O documentário re-apresenta o mundo histórico, fazendo um registro indexado dele; ele representa o mundo histórico, moldando seu registro de uma perspectiva ou ponto de vista distinto" (NICHOLS, 2005 , p. 67, grifos do autor).

Portanto, esta imagem técnica digital pós-fotográfica não está aqui sendo colocada apenas por um viés tecnicista, no sentido de sublinhar a disseminação de operações até então acessíveis apenas a campos especializados de conhecimento, mas também como forma de expressão da contemporaneidade, um signo para o atual cenário pós-moderno e intermidiático. Mesmo que ainda se desconfie de seu caráter autônomo como processo de criação, ou seja, o quanto sua produção estaria contaminada pelo próprio proceder da máquina em detrimento do protagonismo do seu autor. Um receio de que um automatismo mecânico neutralizasse a inventividade, como já havia sido salientado pelo filósofo Jean Baudrillard ao considerar que

Textos, imagens, filmes, discursos, programas saídos do computador são produtos maquínicos, com as devidas características: artificialmente expandidos, levantados pela máquina, filmes repletos de efeitos especiais, 
textos carregados de partes supérfluas, de redundâncias devidas à vontade maligna da máquina de funcionar a qualquer preço (é a sua paixão) e à fascinação do operador por essa possibilidade infinita de funcionamento. (BAUDRILLARD, 1997, p. 147)

São ressalvas carregadas por um lastro histórico que vêm desde o século XIX, como aquele difundido com veemência pelo poeta Charles Baudelaire ao tratar especificamente da técnica fotográfica em oposição à pintura:

Estou convencido de que os progressos mal aplicados da fotografia, como de resto todos os progressos puramente materiais, contribuíram muito para o empobrecimento do gênio artístico francês, já tão raro [...]. É fácil perceber que a indústria, ao entrar no âmbito da arte, torna-se a sua mais mortal inimiga, e que a confusão das respectivas funções prejudica o desempenho de ambas. (BAUDELAIRE apud DUBOIS, 2004, p. 42)

Se esta questão hoje parece estar um tanto superada, não seria por algum desfecho epistemológico dado ao assunto, mas, sobretudo, pela constatação de sua inexorável presença nas mais diversas modalidades da produção imagética dos nossos dias. E, assim, como contraponto, teríamos por sua vez a posição defendida por Vilém Flusser, quando o filósofo enaltece a imagem técnica, enxergando-a como o triunfo de um grande embate entre o humano e o maquínico:

Parece, pois, à primeira vista, que programar modelos de vivência é gesto calculador, frio, distante. Na realidade, é ele gesto dramático de luta entre a vivência concreta do programador e a automaticidade fria e calculadora do aparelho. As imagens sintéticas são mais dramáticas que toda a arte do passado. (FLUSSER, 2006, p. 323)

Considerando este contexto em que softwares estão no centro da criação e difusão midiática, daremos destaque aqui aos softwares de simulação e aos videogames, principalmente aqueles orientados pelo conceito denominado como mundo aberto (open world) ${ }^{3}$, que operam como usinas geradoras de imagens 
artificiais intensas e verossímeis a taxas de sessenta ou mais quadros por segundo (fps) capturadas por câmeras virtuais sob o controle dos próprios jogadores. São recursos vistos aqui como o despontar de uma nova imagética que, como matériaprima absorvida pela narrativa documentária, teria o potencial de construir leituras alternativas em relação ao mundo histórico, conforme se observa em algumas iniciativas propagadas pela internet nos últimos anos.

No mundo da comunicação audiovisual de massa, a utilização de imagens sintéticas é algo corriqueiro, seja no cinema de ficção, fato consolidado há muitos anos, ou até nas campanhas publicitárias, que lançam mão do recurso técnico de modelagem 3D não apenas para recriar cenários e sofisticar a aparência de produtos, mas também para "ressuscitar" alguns "garoto(a)s propaganda" que irão vendê-los. Bruce Lee (1940-1973) já vendeu whisky na China (Johnny Walker, 2013) e Audrey Hepburn (1929-1993) já promoveu uma marca de chocolates (Mars, 2012) $)^{5}$. No Brasil, recentemente, por meio de montagem e efeitos de pósprodução, o humorista Mussum (1941-1994) reapareceu em um comercial de automóvel também (Volkswagen, 2013); uma iniciativa que o mercado publicitário brasileiro já havia experimentado outrora, quando, em 1991, o falecido poeta e compositor Vinícius de Moraes (1913-1980) cantou ao lado de Tom Jobim (19271994) em um comercial para TV da cerveja Brahma6.

Cabe também ressaltar que no cinema documentário, enfoque desta argumentação, a encenação e a recriação de contextos estão no seu âmago desde os primórdios. Seja a família esquimó escolhida por Robert Flaherty em Nanook (EUA, 1922), até as atividades laborais nos filmes da GPO7 produzidos por John comerciais do Império Britânico, o escocês John Grierson (1898-1972) e sua equipe passam para o General Post Office (GPO), departamento responsável pelos correios do Reino Unido. A então GPO Film Unit produziu filmes que ficaram marcados na história do documentarismo, dentre eles Night Mail (Basil Wright; Harry Watt, 1936), Coal Face (Alberto Cavalcanti, 1935) e The Song of Ceylon (Basil Wright, 1934); aí permaneceram até 1940, quando a GPO passou para o controle do Ministério da Informação (HARDY, 1979; BARNOUW, 1979). 
Grierson na Inglaterra. Assim, reitera-se aqui que, historicamente, em nome de sua retórica, o documentário sempre manejou elementos das mais diversas origens na composição da sua narratividade. A apropriação e a reacomodação da imagem é algo inerente ao processo de construção de seus enunciados e os exemplos permeiam toda sua história.

Nos anos 1960, época em que a linguagem do documentário almejou um enlace mais rico e complexo com o real, como o Cinéma Vérité francês, o Cinema Direto norte-americano, o Candid Eye canadense ou o Free Cinema inglês, havia também uma vertente que preservara procedimentos de encenação e reconstrução de ambientes daquele cinema documentário primevo. São documentários de cunho histórico e perspectiva didática, cuja intenção era debruçar-se sobre episódios do passado ao reencená-los para o público televisivo. Algo como fez Peter Watkins na emissora de TV inglesa BBC em filmes como Culloden (Inglaterra, 1964), que abordava a massacrante vitória inglesa sobre os clãs escoceses das highlands. Porém, ali, Watkins modelou a narrativa na forma de reportagem, oferecendo algo muito semelhante aquelas às quais o público inglês assistia naquele mesmo aparelho de TV. E, desta maneira, se ressignificava aquele passado histórico com o presente dos noticiários que cobriam a Guerra do Vietnã então em curso.

No ano seguinte, Watkins realiza The War Game (Inglaterra, 1965), uma aterradora investigação sobre os efeitos que teria um ataque nuclear ao Reino Unido. Em ambos os filmes emula-se a forma de uma "reportagem", caracterizada pela encenação de um repórter-cinegrafista no interior da ação, a câmera livre que parte em busca dos melhores enquadramentos e as entrevistas contaminadas pela tensão das circunstâncias. Assim, Watkins intensifica sua retórica ao introduzir um "efeito real" não apenas pelos temas em evidência, mas pela maneira como eles são apresentados; incorporando como um padrão de linguagem audiovisual que estava adentrando o cotidiano do público que acompanhava, principalmente, os noticiários televisivos.

Naquele mesmo período, um caminho distinto de apropriação de uma imagética circulante pode ser observada em Cuba, quando Santiago Álvarez (1919-1998) que, 
durante três décadas, além de diversos documentários, dirigiu o principal cinejornal da ilha - o Noticiero ICAIC Latinoamericano ${ }^{8}$-, realiza filmes como L.B.J. (Cuba, 1968), uma crítica sarcástica e acusatória ao então presidente estadunidense Lyndon Baines Johnson. O curta-metragem, ao longo dos seus dezoito minutos, adota a premissa conspiratória que circulava na época, colocando Johnson como o verdadeiro mandante dos assassinatos do presidente John F. Kennedy, em 1963, de seu irmão, o senador Robert F. Kennedy, e do ativista Martin Luther King Jr.; tendo sido, os dois últimos, mortos naquele mesmo ano de 1968.

L.B.J. é a abreviação de Lyndon Baines Johnson (1908-1973), deputado e senador texano que se tornou o vice-presidente de John Kennedy, assumindo a Presidência após seu assassinato, em 1963. Ao completar o mandato deixado vago por Kennedy, Johnson se reelege presidente, cargo que ocuparia entre 1963-1969. Um período conturbado na história dos Estados Unidos, lembrado pelos movimentos em apoio aos direitos civis e pelas incertezas da Guerra Fria e da Guerra do Vietnã, a qual foi intensificada por Johnson - fato que marcou negativamente sua imagem, dentro e fora dos EUA.

Os motivos que geraram essas especulações fogem ao escopo deste texto, contudo, é preciso destacar que o filme de Álvarez constrói um outro ponto de vista, divergente da versão oficial difundida pela imprensa internacional. Em grande parte, esta construção se dá com a adoção do recurso técnico do table top, em que a câmera perscruta fotografias em movimentos de varredura potencializados por zoom in e zoom out. Este efeito vai compondo o enredo ao conduzir o olhar do espectador para o que o diretor quer destacar como mais relevante na imagem, que nem sempre é aquilo que está no centro da foto. O movimento de câmera "edita" e dá dinâmica à cena sincronizada ao ritmo da música. aproximadamente 10 minutos cada. Santiago Álvarez e equipe viajaram por mais de noventa países na cobertura de desastres naturais, guerras e eventos político-sociais. Em 2009, foi reconhecido pela UNESCO como um acervo a ser incorporado ao Memória do Mundo, um programa criado em 1992 que visa preservar o patrimônio documental da humanidade (PRIOSTE, 2014). 
Logo no início, antes dos créditos, uma frase em letras vermelhas sobre um fundo branco denota o tom sarcástico do que virá a seguir: "O instituto cubano de arte e indústria cinematográficos tem a honra de dedicar este filme a um dos estadistas mais ilustres de nosso século, por suas excelsas virtudes cidadãs e por sua relevante devoção à humanidade" (tradução nossa) ${ }^{9}$. Surge então o logotipo da revista Life, numa edição de 1966, que revela a origem das imagens, embora os créditos as mencionem apenas como revistas extrangeras.

São fotografias de uma cerimônia de casamento e o intuito parece ser o de apresentar o lugar social do presidente. Um zoom out revela uma igreja extraída de uma matéria que cobriu o casamento da filha de Lyndon Johnson, Luci Baines. A música é um trecho coral de Carmina Burana de Carl Orff e o tom é denso e sombrio, remetendo a tradições medievais. Esta sonoridade vai pontuar diversas passagens, sempre com o intuito de promover um efeito dramático.

Repentinamente, há um corte para o logotipo da revista Playboy, imagens de mulheres seminuas e o som de risadas ao fundo. Álvarez propõe, aqui, um contraste entre o ritual católico - o cerimonial do casamento - e a representação da luxúria, indicando uma hipocrisia que circundaria o mundo do personagem.

Depois de mais algumas imagens da cerimônia, entra a sequência distorcida e colorizada em tons vermelhos de um filme de gângster. Trata-se de Scarface (EUA, 1932), de Howard Hawks, e a sequência é aquela em que o personagem interpretado por Paul Muni sai atirando com sua metralhadora de dentro de um bolo de festa contra os convidados.

Desta maneira, todo o enredo vai sendo construído sem locução ou textos explicativos. É desnecessário descrever todas as passagens para observar que signos vão sendo reapresentados e recontextualizados, gerando novos ordenamentos lógicos de entendimento. A imagética tecida para desmoralizar a figura presidencial arremessa de volta os filmes de Hollywood, as matérias das revistas Life, Playboy, 
dentre outras, produtos da cultura de massa circulantes à época, devolvidos e devidamente reabilitados pelos novos significados.

Dando continuidade a esta breve reflexão, nos deslocamos para um outro momento histórico em que filmes de caráter mais intimista e performativos também incorporaram elementos de uma imagética corrente para potencializar sua proposta. Exemplo, aqui, é o longa-metragem Tarnation (EUA, 2003), um registro reinventado da vida de seu próprio diretor Jonathan Caouette. Rapaz norteamericano, Caouette se filmou nas mais diversas circunstâncias durante 20 anos (desde os 11) para converter em um enredo sobre sua história, particularmente sua relação com a mãe e os avós. Neste caso, foi a linguagem adotada por Caouette, referenciada na televisão, nos videoclipes e nos filmes B, que foram alinhavados numa intensa e provocativa estrutura narrativa.

Tarnation, ao ser integralmente montado em um computador caseiro instalado no quarto do diretor, além de trazer questões vigentes até hoje sobre o papel da subjetividade no cinema documentário contemporâneo, ressalta a autoria mediada pelas tecnologias digitais, apontando as possibilidades e a autonomia que estes sistemas passariam a oferecer ainda mais nos anos seguintes.

Com um custo inicial de US\$218,00, todo o filme foi montado em um computador Apple Macintosh com o software iMovie. Exibido pela primeira vez no festival Mix New York em Novembro de 2003 e, depois, em 2004 no festival de Sundance, recebeu um aporte de US\$500 mil dos diretores John Cameron Mitchell e Gus Van Sant, que entraram como produtores executivos para aprimorar a qualidade do material proveniente de antigos formatos de imagem, converter no formato $35 \mathrm{~mm}$ para exibição no festival e pagar os direitos autorais das diversas músicas, trechos de filmes e programas de tv utilizados (MELLO, 2007).

O material que Caouette tinha em mãos era extenso e das mais diversas origens. Eram mais de 160 horas de material bruto divididas em super-8, betamax, VHS, HI-8, mini-dv e fitas cassetes de áudio (MELLO, 2007). Reconhecido na época como um representante "[...] da ode ao tarde-da-noite-em-meu-quarto-comtecnologia-barata, um bardo do vir-a-ser adolescente, mas com a sensibilidade 
texana e um toque da decadência de Tennessee Williams [...]" (RICH, 2005, tradução nossa) ${ }^{10}$; o processo de produção de Tarnation colaborou para transformá-lo numa celebridade dentro do meio cinematográfico, na época em que o filme foi lançado. Curiosamente era isso que alardeava o texto publicitário disponível no website da empresa Apple, fabricante do equipamento e do software utilizado por Caouette:

Qualquer um é diretor. Verdade. Com iMovie, produzir um grande filme é simples como arrastar e soltar. Arraste seus melhores videoclipes para a área de projeto. Solte nela transições, efeitos e letreiros projetados pela Apple, e sua trilha sonora favorita do iTunes. Então agende sua estreia. ${ }^{11}$ (APPLE, 2007, tradução nossa)

Mais do que um documentário autobiográfico, Tarnation conta a história da mãe do diretor, Renee LeBlanc. Nascida no Texas, Renee, na infância e adolescência, torna-se garota propaganda ao ser descoberta por um fotógrafo em Nova York. Após uma queda que a faz ficar imobilizada por seis meses; por indicação de um vizinho amigo da família, ela passa a receber choques elétricos em uma clínica para acelerar sua reabilitação. Entretanto, o resultado desses choques foi um completo abalo à sanidade mental de Renee, que passa a ser constantemente internada em hospitais psiquiátricos e nunca mais se recupera plenamente. Durante este período, Renee se casa com o pai do diretor, que a abandona em seguida; situação que piora após um estupro sofrido por ela na presença do então pequeno Caouette. Este, passaria a viver com os avós e desenvolveria uma aparente instabilidade emocional. Caouette sai em busca de um culpado para os males que o afligem. Um processo de expiação que culmina com a acusação direta aos avós - que agora são alçados à condição de vilões no mundo de Caouette - pelos maus tratos aplicados à filha. adolescence coming into being, but with Texan sensibility and a touch of Tennessee Williams [...]". 
A estrutura do filme forma-se por um longo flashback. No início, acompanhamos Caouette atendendo um telefonema em que fica sabendo de uma overdose por medicamentos de sua mãe. A partir de então, um travelling feito de dentro do ônibus que o conduz arremessa o espectador para as reminiscências do diretor, em que a história passa a ser contada por meio de intertítulos em ordem cronológica, desde o casamento dos avós.

Os personagens são apresentados como gestados em uma ficção que tem seu protagonista heroico e a vilania dos seus antagonistas, o que nos leva a entender que o sentido maior talvez estivesse em dar vazão na tela àquilo que não poderia ocorrer nas vidas ordinárias daquela família texana, instaurando um espaço de fantasia ao apropriar-se da cultura pop audiovisual. Como um Narciso que contempla seu reflexo na lente de sua câmera, Tarnation alinha-se com precisão ao que estaria por vir; uma sociedade marcada pelo hedonismo desmedido, tão bem representada hoje pelas redes sociais e outros fenômenos de internet.

Voltando à questão da imagem técnica digital, mais recentemente, inúmeros documentários a tem incorporado como recurso na viabilização de seus intentos, como o curta-metragem dirigido por Gabriel Mascaro, As aventuras de Paulo Bruscky (Brasil, 2010). Aqui, Mascaro fez uso da plataforma de interação tridimensional, o Second Life, para dar o feitio necessário à imaginação do artista pernambucano Paulo Bruscky (1949-). Como artista, inventor e performer, Bruscky carrega no amplo conjunto de sua produção a subversão ao uso convencional dos sistemas comunicacionais, como a Arte Postal, os filmes em xerox, os outdoors e tantos outros mais.

No filme de Mascaro, o artista pernambucano passeia pelas suas reflexões sobre arte, cultura e sociedade que se materializam e compõem o ambiente, como o trecho em que afirma que os "[...] historiadores nem sempre falam a verdade, então é a arte que deixa um registro da História mais bem feito, mais real". Logo, tudo se funde na mesma matéria, não há mais limites físicos entre a câmera, o espaço e seu personagem, que está reconstruído como imagem 
digital tridimensional (Figura 1) para assim escapar do mundo histórico. Em um determinado trecho, ele fala sobre um de seus projetos: a criação de um filme sem câmera, sem projetor, sem película, com imagens presas aos batentes do trilho do trem, vistas pelo movimento do próprio ao ter seu piso vazado. Seria um filme apartado do dispositivo, algo que se efetiva pelo próprio documentário ao concretizar a proposta do artista.

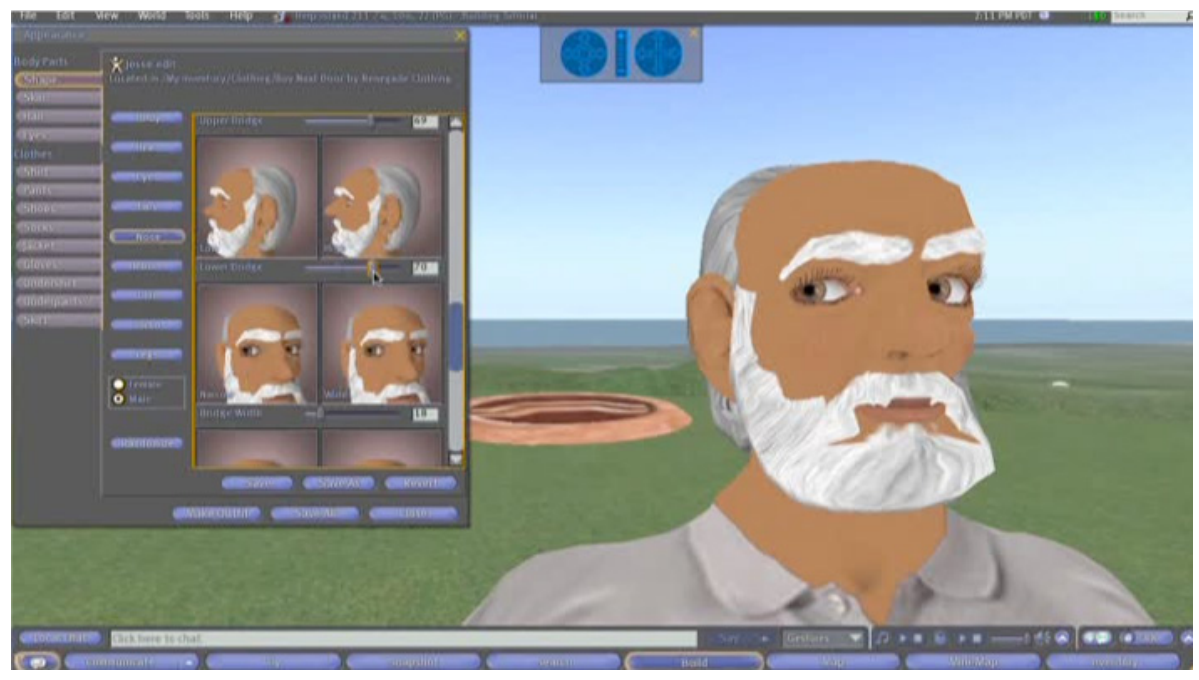

Figura 1: O artista Paulo Bruscky como personagem no software Second Life.

Fonte: Filme As aventuras de Paulo Bruscky (Brasil, 2010).

Desta maneira, se a imagética digital foi adotada por Mascaro como veículo para corporificar o pensamento e os anseios do artista pernambucano, algo inverso ocorre nos procedimentos realizados pelo cineasta e teórico alemão Harun Farocki (1944-2014). Na videoinstalação Parallel (Alemanha, 2012-2014), Farocki produz quatro vídeos que abordam temas como "elementos", "espaços", "movimentos" e "personagens" para refletir por meio de uma narração sobre como as imagens pós-fotográficas, geradas no interior dos games, traduzem a seu modo impasses e inquietações da condição pós-moderna quando, por exemplo, desestabilizam o olhar do espectador ao oferecer-Ihe a possibilidade de contemplar uma mesma cena sob diferentes ângulos e condições.

Nos dias de hoje, a apropriação da imagética pós-fotográfica para criação de narrativas circula intensamente pela rede e está cada vez mais próxima do 
espectador comum. São os denominados machinimas que, se por vezes ainda não contemplam uma interação muito rica com personagens - uma vez que os enquadramentos previstos para câmera ainda valorizam o distanciamento, colocando em evidência cenários e ambientes -, por outro lado já são capazes de fornecer uma miríade de elementos visuais capazes de contextualizar narrativas e ambientar uma grande diversidade de enredos. Há diversas produções em machinimas geradas para "documentalizar" ou elaborar como ficção desde situações mais prosaicas do universo juvenil, como inadequação social, até casos como violência doméstica e abusos. Um dos softwares mais utilizados neste tipo de produção é o The Sims, um simulador de vida em sociedade lançado no ano 2000 que permite ao jogador administrar agentes virtuais, desde as funções fisiológicas mais básicas até aspectos emocionais e comportamentais.

Um dos pioneiros nesta proposta dos machinimas serem um campo de criação para autores sem acesso aos meios de produção audiovisual é o curtametragem The french democracy (França, 2005) (Figura 2), dirigido por Koulamata, pseudônimo de Alex Chan, francês, descendente de chineses, com 27 anos na época e sem qualquer experiência cinematográfica anterior. O título carrega uma ironia ao contar os acontecimentos ocorridos em outubro de 2005, quando uma convulsão social tomou as ruas de diversos subúrbios em Paris. Chan teve a iniciativa de fazer The french democracy ao acompanhar os juízos de valor emitidos pela mídia que cobria o episódio.

O estopim foi a morte de dois jovens, Zyed Benna e Bouna Traoré que, após fugir de uma abordagem policial, foram eletrocutados ao se esconderem numa subestação de eletricidade.

Feito em quatro dias com o software The Movies e legendas em um inglês simplista por não ter um microfone disponível, The french democracy foi disponibilizado no site da produtora do game (Lionhead) e teve imensa repercussão. Principalmente ao explicitar pelas próprias vítimas toda a discriminação racial, cultural, religiosa, além de todos os problemas sociais e a violência policial a que estavam submetidos cotidianamente. 


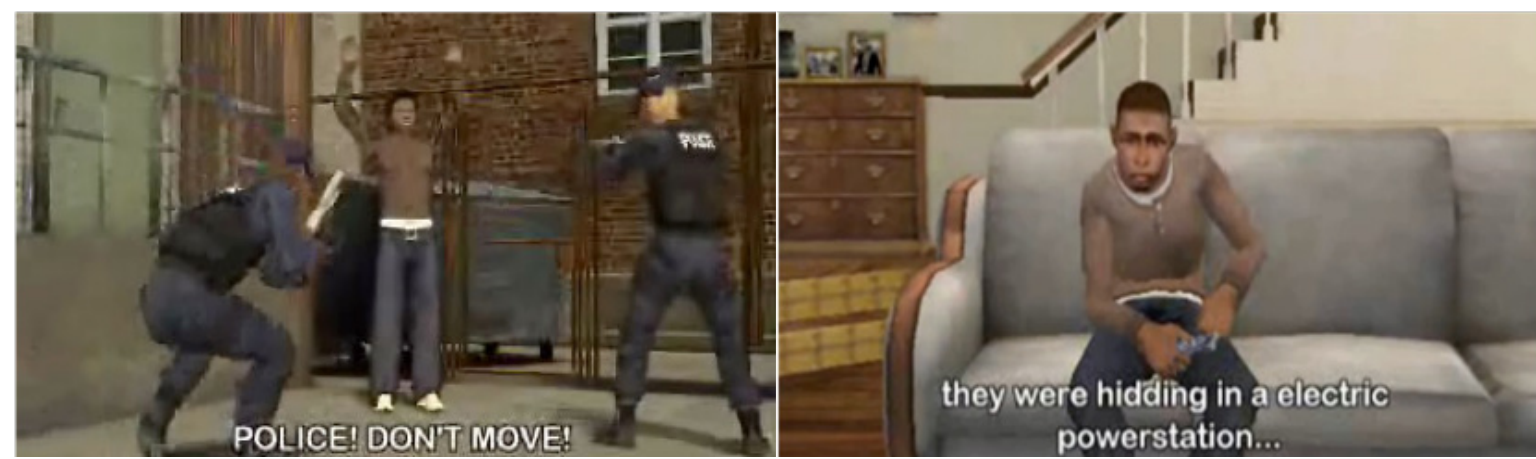

Figura 2: Cenas do curta-metragem The french Democracy (França, 2005)

Fonte: Disponível em: <http://bit.ly/2OfLWzw>. Acesso em: 5 nov. 2018

Ao final do curta-metragem é feita uma homenagem a Benna e Traoré e, assim, por meio do despojamento amador de uma imagem técnica digital ainda precária, mas que estava presente no cotidiano dos garotos dos subúrbios parisienses, despontou uma das mais legítimas formas de se lamentar a ausência dos tão aclamados ideais franceses de liberdade, igualdade e fraternidade.

Como no universo dos games transcorre um processo intenso e contínuo, em que a cada nova versão de um produto a imagem pós-fotográfica ganha intensidade e fidedignidade, há um imenso manancial aberto para criação de outras produções audiovisuais, uma espécie de usina geradora de enquadramentos a partir das movimentações de uma câmera virtual manipulada pelo jogador. Isto faria com que documentários de reconstituição histórica se tornassem possíveis de serem realizados com, por exemplo, games como Assassin's Creed ${ }^{12}$, cujas versões costumam trazer uma meticulosa reconstituição de época por onde circulam personagens célebres. A versão lançada em 2015, denominada Syndicate, que se passa em Londres durante a revolução industrial, não deixa de representar a formação da classe operária e ter como personagens a Rainha Vitória, o naturalista Charles Darwin, o escritor Charles Dickens e até mesmo o filósofo Karl Marx (Figura 3). 


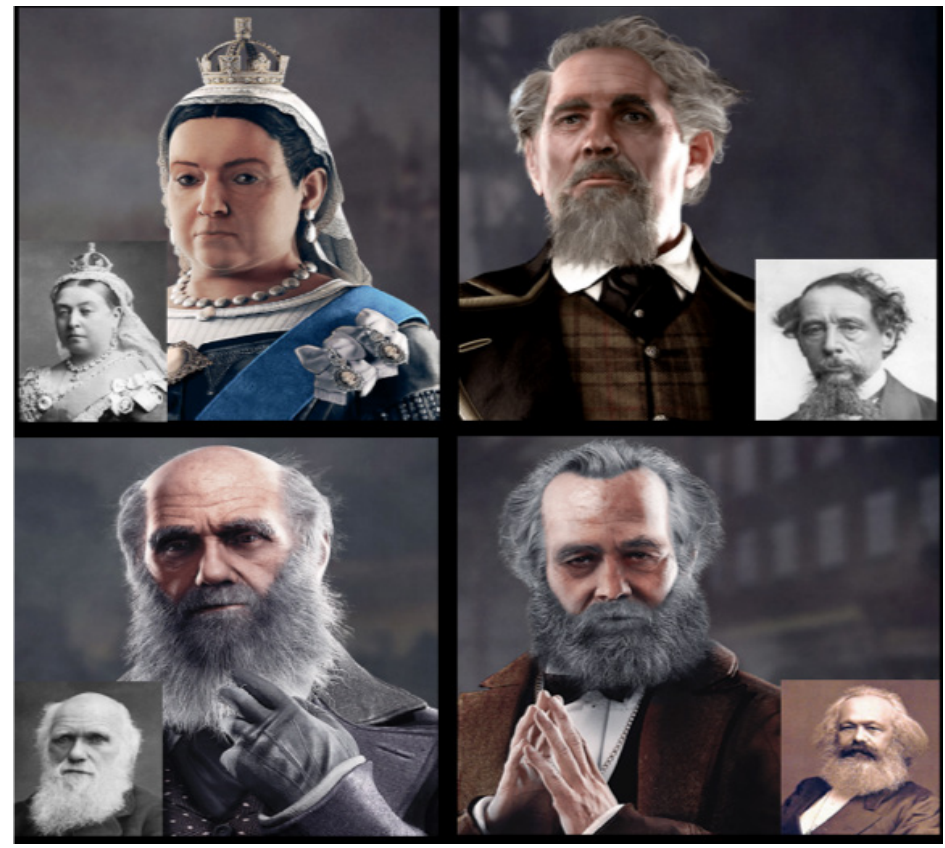

Figura 3: Personagens históricos no game Assassin's Creed, edição Syndicate (2015), a Rainha Vitória (1819-1901), Charles Dickens (1812-1870), Charles Darwin (1809-1882) e Karl Marx (1818-1883)

Fonte: Assassins Creed. Disponível em: <https://www.ubisoft.com/pt-br/game/ assassins-creed-syndicate/>. Acesso em: 5 nov. 2018

Porém, há um caso em que este potencial começa a ser explorado, como no curta-metragem Stigler (EUA, 2013)13, dirigido e produzido por Nick Gillin (pseudônimo "Nassault"), um estudante de cinema na Art Center College of Design em Pasadena, Califórnia. Realizado com o War Thunder ${ }^{14}$, um simulador multiplayer de combates aéreos e terrestres inspirado na Segunda Guerra Mundial e produzido pela desenvolvedora de softwares russa Gaijin, Stigler, nos seus pouco mais de oito minutos de duração, reencena um episódio ocorrido em território alemão que ganhou muita notoriedade pelo seu desdobramento nos anos posteriores.

No início do filme, um introito na forma de intertítulo com letras brancas em fundo preto anuncia: 
Em 20 de dezembro de 1943, depois de um bem-sucedido bombardeio à cidade de Bremen, a "fortaleza voadora" de Charles 'Charlie' Brown foi seriamente danificada pelos caças alemães. Detectando o B-17 de Charlie sozinho, e isolado atrás, o piloto da Luftwaffe e ás Franz Stigler tinha uma oportunidade de abater o debilitado bombardeiro ${ }^{15}$. (STIGLER, 2013, tradução nossa)

Em seguida somos deslocados à cidade alemã de Bremen, em que cenas do céu a partir de uma paisagem rural nevada são vistas do solo para logo em seguida surgirem aeronaves de combate em posição de ataque. Ao som de gritos, por alguns segundos a câmera em solo oscila em planos fechados e desfoques que tentam registrar em vão um grupo de soldados manuseando um canhão antiaéreo para dissuadir o ataque, que é inevitável. A câmera assume agora o espaço aéreo e o ponto de vista dos bombardeiros, que despejam sua carga letal por sobre a cidade. Em seguida, um enquadramento com a linha do horizonte ao fundo mostra a retirada das aeronaves após o ataque e a reação dos caças alemães, dando início a um intenso combate aéreo que nos é apresentado por uma câmera trêmula que, por vezes, está em solo e, por vezes, assume o ponto de vista dos pilotos. Neste trecho, torna-se importante ressaltar que, se o ambiente é uma reconstrução digital de batalha, a instabilidade da imagem não é um mero falseamento de toda tensão em curso, pois a natureza da câmera virtual está indiscernível naquele espaço arquitetado, ou seja, é sensível aos mesmos efeitos que os outros elementos de cena.

Após o combate, vemos o B-17 voando sozinho e muito avariado. Ouve-se a voz dos pilotos no rádio sendo instruídos para retornarem à base com segurança. Vemos então um caça alemão aproximar-se do B-17. Em seguida, a câmera assume o ponto de vista do piloto Franz Stigler, que coloca a aeronave norte-americana sob a mira de seu armamento. Para acentuar o plano subjetivo e superar as limitações que o software oferece no que diz respeito à caracterização física de 
personagens, ouvimos apenas a respiração profunda e ansiosa do piloto. Vemos então que o mesmo se aproxima, chegando a estabelecer um contato visual entre os pilotos, emparelhando os aviões. Enquanto esta aproximação transcorre, um texto se sobrepõe à cena com a declaração do piloto alemão, reiterando o que foi mostrado: "Eu não tive coração para executar aqueles bravos homens. Voei ao lado deles por um longo tempo. Eles estavam tentando desesperadamente chegar à casa, e eu estava deixando-os fazer isso. Eu não poderia ter atirado contra eles."16 (STIGLER, 2013, tradução nossa).

Por fim, um outro intertítulo anuncia o desfecho, dizendo que, entre 1990 e 2008, Charlie Brown e Franz Stigler se tornaram amigos íntimos e assim permaneceram até a morte de ambos no ano de 2008. Haviam se reencontrado somente 47 anos depois, nos Estados Unidos, num encontro de ex-combatentes (MAKOS; ALEXANDER, 2012). Ao final, uma fotografia mostra os dois ex-pilotos idosos sendo homenageados em um evento (Figura 4), uma foto que tem o efeito de articular uma reconexão com o mundo histórico ao instaurar um novo espaço em que passado, presente, real e simulado se fundem organicamente.

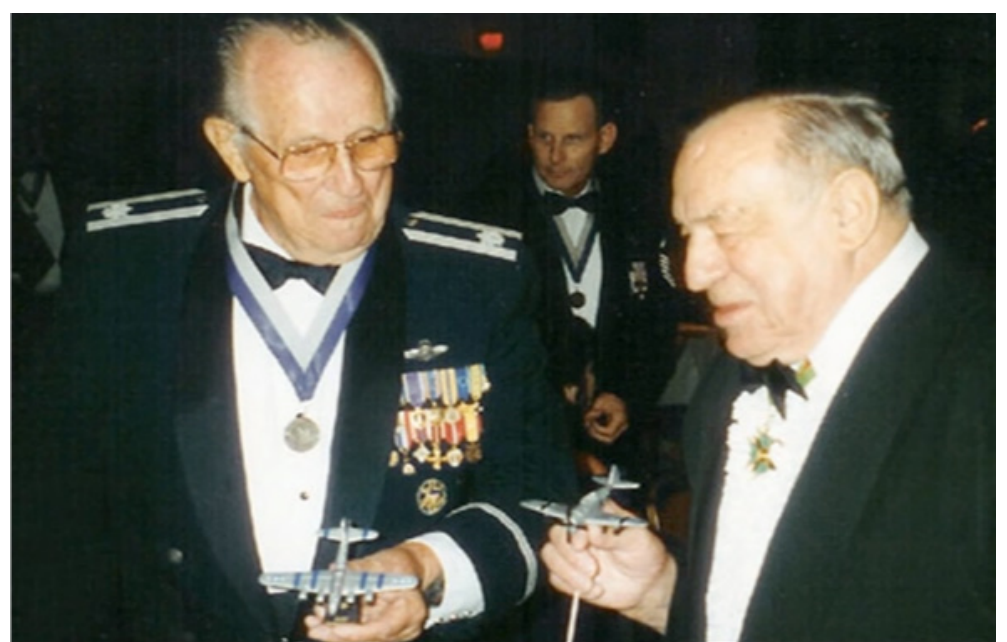

Figura 4: Fotografia dos ex-pilotos Charlie Brown e Franz Stigler na cena final. Fonte: Stigler (EUA, 2013) 
Portanto, conclui-se que, mesmo sendo uma obra despretensiosa pelas limitações de uma narrativa que teve de apelar a textos para exprimir-se e a um tom evidentemente romantizado que floreia relatos de guerra - efeito reforçado pelas canções ao estilo New Age ${ }^{17}$ - , Stigler, ainda assim, carrega uma proposta instigante. Primeiramente, por demonstrar o protagonismo dos videogames na ascensão da imagem pós-fotográfica, tornando desnecessários dispendiosos orçamentos para reconstituições históricas, o que consequentemente coloca ao alcance de muitos o potencial para (re)contar fatos, refazer versões e reinterpretar relatos do mundo. Mas, além disso, também nos faz refletir sobre toda a tradição fundada no estatuto da câmera como captador e organizador de fenômenos. Nos procedimentos dos machinimas, a câmera é agora parte integrante da diegese fílmica, a matéria da câmera e do seu registro é a mesma do ambiente filmado, numa inusitada ocorrência em que o filme engendra sua própria câmera.

\section{Referências}

APPLE. Apple, 2007. Disponível em: <http://apple.com>. Acesso em: 12 jul. 2007.

BARNOUW, E. Documentary: a history of non-fiction film. New York: Oxford University press, 1979.

BAUDRILLARD, J. Tela total, mitos-ironias de era do virtual e da imagem. Porto Alegre: Sulina, 1997.

CHANAN, M. The politics of documentary. London: British Film Institute, 2012.

DUBOIS, P. Cinema, vídeo, Godard. São Paulo: Cosac Naif, 2004. 
FAROCKI, H. Desconfiar de las imágenes. Buenos Aires: Caja Negra, 2013.

FLUSSER, V. Sintetizar imagens. In: FABRIS, A; KERN, M. L. B. (Orgs.). Imagem e conhecimento. São Paulo: Edusp, 2006.

HARDY, F. (Org.). Grierson on documentary. London: Faber and Faber, 1979.

MACHADO, A. O sujeito na tela. São Paulo: Paulus, 2007.

MAKOS, A. ; ALEXANDER, L. A higher call: an incredible true story of combat and chivalry in the war-torn skies of world war II. New York: Berkley Caliber, 2012.

MELLO, M. Os tormentos de Caouette. Revista Teorema: Crítica de cinema, n. 11, p. 44-48. Porto Alegre, set. 2007.

MORAN, P.; PATROCINIO, J. (Orgs.). Machinima. São Paulo: Cinusp, 2011.

MORAN, P. Deslocamentos de Paulo Bruscky por Gabriel Mascaro: um documentário no Second Life. Revista Z Cultural, Universidade Federal do Rio de Janeiro, Rio de Janeiro, ano VIII, n.1. Disponível em: <http://bit.ly/2Q5hXfu>. Acesso em: 20 abr. 2018.

NICHOLS, B. Representing reality. Bloomington: Indiana University Press, 1991. . Introdução ao documentário. Campinas: Papirus, 2001.

NÓVOA, J.; ; FEIGELSON, K.; FRESSATO, S. B. (Orgs.). Cinematógrafo: um olhar sobre a história. Salvador: EdUfba; São Paulo: Editora da Unesp, 2009. 
PRIOSTE, M. O cinema documentário de Santiago Álvarez na construção de uma épica revolucionária. 2014. 248 f. Tese (Doutorado) - Programa de Pós-Graduação em Meios e Processos Audiovisuais, Escola de Comunicações e Artes, Universidade de São Paulo,.

RICH, B. R. Tell it to the camera. Sight \& Sound Magazine, British Film Institute, London, abr. 2005. Disponível em: <http://bit.ly/2P0zmcy>. Acesso em: 20 jul. 2016.

submetido em: 24 abr. 2018 | aprovado em: 08 jun. 2018 